\title{
Intercultural Competence Past, Present, and Future: Respecting the Past, Problems in the Present, and Forging the Future
}

Edited by

María Dolores López-Jiménez

Universidad Pablo de Olavide, Sevilla, Spain

Jorge Sánchez-Torres

Centro Internacional de Estudios Culturales, Sevilla, Spain

ISBN: 978-981-15-8245-5

2021, Springer

Reviewed by Vander Tavares, Faculty of Education, Høgskolen i Innlandet (Inland Norway University of Applied Sciences).

Intercultural Communication and Language fducation

Maria Dolores López-Jiménez Jorge Sánchez-Torres Editors

\section{Intercultural} Competence Past, Present and Future

Respecting the Past, Problems in the Present and Forging the Future

Q Springer
In an era of intense global mobility, intercultural competence emerges as an even more critical expertise of the transnational individual. After all, intercultural competence has been linked to positive development in the social, cultural, psychological, and linguistic domains - or, in other words, essentially to a holistic development-for the individual (Root \& Ngampornchai, 2013; Soria \& Troisi, 2014). Furthermore, as institutions of higher education continue to see increased diversity on their campuses, intercultural competence plays an essential role in preparing local and global communities to understand, respect, and celebrate difference. However, how intercultural competence may be defined, taught, and learned remains a complex area of investigation and 
discussion in applied linguistics, despite the decades-long scholarly engagement with the topic from multidisciplinary perspectives. In this innovative and accessible volume, López-Jiménez and Sánchez-Torres help decipher some of the complexity revolving around the teaching and the acquisition of intercultural competence with contextualized investigations that address a range of issues primarily within applied linguistics. As such, this volume will be of great interest to second/foreign language teachers and language teacher educators, especially since much of the investigation presented in this volume is grounded in teacher research - an approach to research that still faces issues of legitimacy. Indeed, this volume marks one step forward in confronting the legacy of a Western-centric vision for applied linguistics that has affected particularly the teaching of culture in the field. As the editors rightly explain, the teaching of culture has traditionally neglected cultural contexts of the global south through its one-size-fits-all approach.

The editors begin by undertaking the laborious task of unpacking the intricate historical development of the construct of intercultural competence and its interrelated notions. It is precisely through such detailed review that the editors are able to place their timely contribution within the literature in response to "an urgent need for theoretical frameworks and pedagogical suggestions for developing intercultural competence" (p. 6). To meet the need for refined conceptual frameworks and teaching tools for intercultural competence, and consequently, for a better understanding of how language, culture, and identity intersect in second/foreign language education, the editors have structured the volume into two parts. The first part, titled "Respecting the Past and Problems in the Present," presents six chapters that allow us to understand the conceptual and practical development of intercultural competence, especially the ways in which different practices and approaches have evolved. The second part, titled "Forging the Future," presents five chapters that explore teachers' perspectives on intercultural competence, and in doing so, puts forth "tools that could not only model further actions in education, but also forge part of the uncertain future" ( $p$. 16). By organizing the chapters in the volume as a continuum, the editors reveal which issues continue to deserve scholarly attention.

Another strength of the volume lies in its diverse approach to exploring intercultural competence and its connecting aspects. The educational settings considered include study abroad education, local regular/mainstream education, after-school, online, and Content and Language Integrated Learning (CLIL) education, within different (1) educational contexts, such as community schools, primary, secondary, and tertiary, and (2) linguistic contexts, such as foreign, second, and heritage. Additionally, this volume brings qualitative and quantitative research together from different countries, among them Australia, New Zealand, Great Britain, Spain, Finland, the United States, Portugal, Japan, Hong Kong, and Germany. Apart from the introduction, (inter)cultural awareness development is explored in Chapters 2 and 3 from a perspective of heritage language education. Chapters 4 and 5 demarcate the switch to themes in the present (the editors have classified heritage languages as more strongly representing a link to the past in terms of intercultural awareness education) and consider issues of student integration and motivation. Chapters 6 and 7 investigate the ways in which 
teaching practices can be (dis)connected to students' experiences of intercultural competence outside the classroom. Chapters 8 and 9 delineate a look to the future, and examine, in a case-study-like format, how the knowledge, attitudes, beliefs, and awareness of current English as a foreign language teachers can foster critical cultural awareness in future intercultural education. The final three chapters present analyses of trends that directly relate to intercultural education in the decades ahead, including the role of online learning in and the impact of creative instructional tools on the development of intercultural competence.

The rigorous research behind this volume enables it to enrich the current debates relating to intercultural competence in applied linguistics from multiple perspectives. This volume is certainly a useful and necessary resource for novice and experienced language teachers alike. From engaging deeply with pressing themes, López-Jiménez and Sánchez-Torres effectively identify some of the questions that will guide the course of research in intercultural education in the near future. Nevertheless, in a volume preoccupied with the trajectory of research and practice in intercultural education across time and space - a trajectory which has traditionally reflected knowledge from the global north - the editors overlook the undeniable need to include investigations from other sociopolitical contexts. In the epilogue, an attempt is made to signal such inclusion by referencing quotes that are supposed to represent voices from South America in a very broad discussion centered on l'état de l'art in applied linguistics. Although the contributing authors to this volume embody great linguistic and cultural diversity, this collection could have been a platform for empirical investigations that also stem from the global south, thus promoting academic social justice on a large, political level. Intercultural competence is, among many things, about the relationship between the self and the other. It is through knowledge of the other that we can begin to engage in self-reflection to critically evaluate the role we play in the exclusion/inclusion of the cultural other (Freire, 2000).

To conclude, this volume helps to fill an important gap in the applied linguistics literature. Simultaneously, it signifies progress in the overall debate around the teaching and learning of intercultural competence as it presents promising answers and poses new questions for language teachers, language teacher trainers, and students in the field. In a year contextualized by the farreaching impact of the global pandemic, including increased tension between nations, López-Jiménez and Sánchez-Torres bring an indispensable volume to the table whose research can illuminate educators in their work to prepare better and more engaged global citizens.

\section{REFERENCES}

Freire, P. (2000). Pedagogy of the oppressed: 30th anniversary edition. Continuum. Root, E., \& Ngampornchai, A. (2013). "I came back as a new human being:" Student descriptions of intercultural competence acquired through education abroad experiences. Journal of Studies in International Education, 17(5), 513-532. 
Soria, K. M., \& Troisi, J. (2014). Internationalization at home alternatives to study abroad: Implications for students' development of global, international, and intercultural competencies. Journal of Studies in International Education, 18(3), 261-280.

VANDER TAVARES is currently a Postdoctoral Research Fellow in the Faculty of Education at Høgskolen i Innlandet (Inland Norway University of Applied Sciences). His major research interests include internationalization of higher education and the international student experience; the intersection of language, culture, and identity; and second language acquisition. He is the editor of Multidisciplinary Perspectives on International Student Experience in Canadian Higher Education (IGI Global) and the author of International Students in Higher Education: Language, Identity and Experience from a Holistic Perspective (Rowman \& Littlefield/Lexington Books). Email: vander.tavares@inn.no 